\title{
TRIESTE - CARe: IMPACT OF ADRENALINE ON OUT OF HOSPITAL CARDIAC ARREST OUTCOME
}

\author{
Scapol $\mathrm{S}^{1}$, Rakar $\mathrm{S}^{1}$, Vitrella $\mathrm{G}^{1}$, Fabris $\mathrm{E}^{1}$, Perkan $\mathrm{A}^{1}$, Cageggi $\mathrm{D}^{2}$, Zambon $\mathrm{M}^{2}$, Peratoner $\mathrm{A}^{2}$, \\ Roman Pognuz E ${ }^{3}$, Antonaglia V², Berlot $\mathrm{G}^{3}$, Sinagra G ${ }^{1}$ \\ Department of Cardiology ${ }^{1}$, Emergency Medical System², \\ Institute of Anesthesiology and Intensive Care ${ }^{3}$
}

\section{BACKGROUND}

Current guidelines recommended intravenous adrenaline as a crucial treatment during cardiac arrest resuscitation, suggesting $1 \mathrm{mg}$ every $3-5$ minutes of CPR. Adrenaline is usually administrated in the OHCA with worst prognosis. Observational studies and RCTs have questioned the efficacy of its use and suggested possible negative effects on survival and neurological outcomes.

\section{METHODS}

We analyzed data from our registry Trieste Cardiac Arrest Registry, from 2011 to 2015 we reported all the OHCA of presumed cardiac origin. The goal of our study was to value the impact of adrenaline on survival rate and on neurological outcome.

\section{RESULTS}

The registry contained 544 patients. We excluded patients without adrenaline administration or data(109 pts). We analyzed the administration of adrenaline, timing and dose. We know the administration time of 317 patients, we compare patients who received adrenaline before and after 15 minutes from the time of call but there isn't substantial differences. Only the patients with shockable rhythm who receive adrenaline before 15 minutes had more ROSC (57.5 vs $32 \mathrm{p} 0.031$ ) and survival rate at 30 days fup (32.5 vs $14.7 \mathrm{p} 0.075)$ but there aren't substantial differences at 1year follow-up (12.5 vs $11.8 \mathrm{p} 0.923)$.Comparing the dose of adrenaline ( $\leq$ or $>3 \mathrm{mg}$ ), known in 425 patients, who received less adrenaline $(\leq$ $3 \mathrm{mg}$ ) had more ROSC (49 vs $24 \mathrm{p}<0.001$ ), H discharge (19.7 vs $5 \mathrm{p}<0.001), 30$ days fup (19.4 vs 7.4 p0.002), 1 years follow-Up (13.1 vs 3.3 p0.001) and better neurological outcome CPC 1-2(19.7 vs $4.1 \mathrm{p}<0.001)$.

ADMINISTRATION TIME 317 PTS

\begin{tabular}{lccc}
\hline & $\mathbf{1 5} \mathbf{~ m i n}$ & $>\mathbf{1 5} \mathbf{~ m i n}$ & $\mathbf{p}$ \\
ROSC & 57.5 & 32 & 0.031 \\
30 days & 32.5 & 14.7 & 0.075 \\
\hline 1 year & 12.5 & 11.8 & 0.923
\end{tabular}

DOSE OF ADRENALINE 425 PTS

\begin{tabular}{lccc}
\hline & $\leq \mathbf{3} \mathbf{~ m g}$ & $>\mathbf{3} \mathbf{~ m g}$ & $\mathbf{p}$ \\
ROSC & 49 & 24 & $<0.001$ \\
H discharge & 19.7 & 5 & $<0.001$ \\
30 days & 19.4 & 7.4 & 0.002 \\
1 year & 13.1 & 3.3 & 0.001 \\
CPC 1-2 & 19.7 & 4.1 & $<0.001$
\end{tabular}

\section{CONCLUSION}

Lower and earlier dose of adrenaline is associated with a higher percentage of survival and good neurological outcome only in patients with shockable rhythm, but patients who received less adrenaline are patients in which the chain of survival worked without loosing time. Time of adrenaline is "as soon as possible" but be careful to not overstep the dose. 